\title{
SRAP analysis of brown planthopper (Nilaparvata lugens) populations maintained on differential rice host varieties
}

\author{
CHAERANI", AHMAD DADANG, FATIMAH, BAHAGIAWATI AMIR HUSIN, SUTRISNO, \\ MUHAMAD YUNUS \\ Indonesian Center for Agricultural Biotechnology and Genetic Resources Research and Development. Jl. Tentara Pelajar no. 3A Bogor 16111, West \\ Java, Indonesia. Tel.: +62-251-837973, 833975, Fax.: +62-251-838820, " email: chaeran1 @ yahoo.com
}

Manuscript received: 17 June 2021. Revision accepted: 21 September 2021.

\begin{abstract}
Chaerani, Dadang A, Fatimah, Husin BA, Sutrisno, Yunus M. 2021. SRAP analysis of brown planthopper (Nilaparvata lugens) populations maintained on differential rice host varieties. Biodiversitas 22: 4266-4272. Brown planthopper (Nilaparvata lugens Stål) biotypes differ in virulence to rice varieties carrying different $B p h$ resistance genes. These biotypes are reported can be genetically discriminated against using DNA markers. Four brown planthoppers (BPH) populations, which displayed two virulence phenotypes, have been produced by selection and adaptation on four differential host varieties. Sequence-related amplified polymorphism (SRAP) marker preferentially amplifies the coding regions in the genome and, thus, can discriminate the observed virulence variations among those populations. This study aimed to analyze the genetic variation of four developed BPH populations using SRAP markers. Genetic analysis of a total of $40 \mathrm{BPH}$ females with 18 polymorphic primers revealed equal genetic diversity parameter values among populations (Na: 1.1 to 1.4 , Ne: 1.2 to 1.3 , I: 0.22 to 0.29 , He: 0.14 to 0.18 , and UHe: 0.15 to 0.19 ). Analysis of population structure by AMOVA indicated low genetic variation among populations $(9 \%)$. Still, pairwise PhiPT population values between all pairs of the population revealed the presence of moderate genetic differentiations (PhiPT ranged from 0.57 to $0.133, P<0.01$ ). Two partial clusters in plots of PCoA were corresponded to two virulence groups, indicating the ability of SRAP markers to discriminate virulence phenotype. Further selection and adaptation are expected can form four desired virulence patterns with complete genetic separation among the population before its application as resistance screening agents of rice lines.
\end{abstract}

Keywords: Brown planthopper, DNA marker, genetic differentiation, rice, virulence

\section{INTRODUCTION}

Brown planthopper (Nilaparvata lugens Stål, Hemiptera: Delphacidae) is Indonesia's most destructive rice (Baehaki and Mejaya 2015). Recurrent outbreaks of brown planthopper (BPH) in Indonesia are caused by continuous rice cultivation, extensive use, and frequent insecticides (Baehaki and Mejaya 2015). This pest is a typical monophagous vascular feeder of rice (Cheng et al. 2013). Feeding activities by both nymphs and adults on the basal portion of plants result in rapid wilting and complete drying, which is observed as a hopper-burn symptom in rice fields (Bottrell and Schoenly 2012; Cheng et al. 2013; Bao and Zhang 2019). In addition, brown planthopper (BPH) is also a vector of viral diseases. Hence, even at low population densities, $N$. lugens can cause significant losses in rice production when they transmit these viruses (Cheng et al. 2013; Bao and Zhang 2019).

BPH outbreak in tropical Asia was triggered by rice intensification production during the green revolution era in the 1970s and 1980s (Bottrell and Schoenly 2012). Sequential release and continuous succession monoculture planting of resistant rice with Bphland bph2 resistance genes from the International Rice Research Institute (IRRI) throughout tropical Asia to control BPH promoted the selection of local populations capable of feeding on these varieties after only a few years after first adopted by farmers (Bottrell and Schoenly 2012; Horgan et al. 2017).
Field BPH adaptation to these genes occurred within 10 to 20 generations of BPH life cycle (Cruz et al. 2011; Horgan et al. 2017).

Rice breeding centers in Asia have been using the resistance screening methods and its modification developed at IRRI in the 1970s to BPH biotypes with varying virulence to different BPH resistance $(B p h)$ genes (Bottrell and Schoenly 2012). BPH biotypes are numbered according to $B p h$ genes: cultures of BPH not virulent to all $B p h$ resistance genes are designated 'biotype 1', whereas those infectious to Bphl or bph2 are termed as 'biotype 2' or 'biotype 3', respectively (Bottrell and Schoenly 2012). Biotype 4 is virulent to $B p h 1$ and $b p h 2$ but not $B p h 3$ or Bph4 (Bottrell and Schoenly 2012; Kobayashi et al. 2014). 'Biotype 3' was initially produced by continuous adaptation of laboratory-reared colonies on rice variety carrying bph2 (Cheng et al. 2013). Biotype 4 is the most destructive in South Asia and occurs predominantly on the Rathu Heenati variety (Cheng et al. 2013). BPH biotypes do not differ significantly in morphology and biochemistry, overlap in cytological characters and acoustic behavior, display slight genetic divergence among biotypes based on morphological characters, and have no mating barriers (Kobayashi 2016).

In Indonesia, field populations with 'biotype 3' virulence patterns were dominant in 2006, and 'biotype 1' has extinct, but 'biotype 4' virulence phenotypes emerged in 2010 in few provinces of Indonesia (Baehaki 2012a). 
Later surveys indicated that field populations with multiple virulences by overcoming bph4, bph5, Bph6, bph7, Bph9, or $b p h 2+B p h 3$ genes were distributed in Java and South Sulawesi (Chaerani et al. 2016). A similar trend was also observed in other countries of Asia where bph5, bph7, Bph8, Bph9, Bph10, and Bph18 genes are also ineffective against field BPH population (Cruz et al. 2011; Horgan et al. 2015).

Because of rapid adaptation of field $\mathrm{BPH}$ virulence in Indonesia, stringent resistance screening of promising rice lines has been obliged before its registration and release by the use of BPH biotype 1, 2, and 3, as well as a representative field population as the screening agents (Sasmita et al. 2019). However, during laboratory rearing, the virulence characteristics of BPH biotypes may be unstable (Manzila et al. 2000; Baehaki and Munawar 2008; Chaerani et al. 2016), and the field population must be replaced with a new one after few generations of rearing (Baehaki 2012b). To address these issues, virulence selection and adaptation on appropriate host variety resulted in four BPH populations (populations T, M, A, and R) with four biotype virulence patterns (Chaerani et al. 2017; Chaerani et al. 2021). However, these populations still displayed two virulence patterns, indicating partial host adaptation.

BPH biotype is merely a population with increased or decreased frequencies of virulence alleles through selection and sympatric speciation (Kobayashi 2016). Therefore, phenotypic plasticity shown by BPH population indicates the change in allele frequencies of genes associated with host adaptation. In several insects, including BPH, DNA marker analysis has been employed to study the divergence of biotypes species to understand the basis, i.e., geographic or host plant-associated differentiation (Wang et al. 2020). However, the first genetic study using random amplified polymorphic DNA (RAPD) markers in BPH did not indicate genetic divergences among BPH biotypes (Shufran and Whalon 1995). Still, the later genetic study suggested that the markers can partially discriminate biotypes 1 and 2 resulted from the purification of contaminated biotype stocks (Bahagiawati and Rijzaani 2005). A more recent study could completely separate four BPH biotypes analyzed with expressed sequence tags-simple sequence repeat (EST-SSR markers) (Jing et al. 2012).

A PCR-based marker system similar to RAPD called sequence-related amplified polymorphism (SRAP) is designed to strengthen the coding regions or the interval between genes and their non-coding flanking regions and tightly links to actual genes ( $\mathrm{Li}$ and Quiros 2001; Li et al. 2014). The SRAP technique uses a 17-bases forward primer and an 18-base reverse primer which amplifies the open reading frames (ORFs) (Li and Quiros 2001). A single forward primer can be combined with numerous, interchangeable reverse primers, resulting in distinct and polymorphic SRAP loci (Robarts and Wolfe 2014). This inexpensive marker is highly reproducible, has less technical efforts, and produces a significantly greater number of variable fragments per locus and a higher rate of polymorphism relative to inter simple sequence repeat (ISSR), RAPD, and SSR markers (Li and Quiros 2001;
Robarts and Wolfe 2014). In addition, SRAP was reported to be more potent than RAPD analysis for detecting the genetic polymorphism among closely related species (ElAzim et al. 2019). SRAP markers have gained popularity in studies of genetic diversity, genetic linkage map construction and comparative genetics in various crops (Li et al. 2014; Robarts and Wolfe 2014) and to a lesser extent in studies of genetic diversity of plantpathogen (Tripathi and Dubey 2015; Longya et al. 2020), insect (Wang et al. 2020) and animal (ElAzim et al. 2019).

A genetic mapping study of biotype 2 virulence genes employed some SRAP markers and found 106 polymorphic markers. Furthermore, one of the SRAP and an SSR marker flanked an interval of $1.1 \mathrm{cM}$ on chromosome 14 where a quantitative trait locus (QTL) with a significant effect $(24 \%)$ on BPH growth rate was detected (Jing et al. 2014). Based on this result, we were interested in testing the SRAP marker's ability to distinguish the virulence variation among the four advanced BPH populations. The objective of this study was thus to analyze the genetic differentiation among the four developed BPH populations using SRAP markers and to relate it with the virulence phenotypes observed among the populations.

\section{MATERIALS AND METHOD}

\section{Brown planthopper population}

The genetic material used in this study consisted of populations $\mathrm{T}, \mathrm{M}, \mathrm{A}$, and $\mathrm{R}$ adapted on differential rice host varieties TN1 (carries no Bph gene), Mudgo (Bphl), ASD7 (bph2), and Rathu Heenati (Bph3, Bph17), respectively. These populations resulted from three to four virulence selection process combined with one selfing in each cycle on appropriate variety from three field populations (Chaerani et al. 2017; Chaerani et al. 2021). Population $\mathrm{T}$ and $\mathrm{A}$ were at the $2 \mathrm{nd}$ and $3 \mathrm{rd}$ generation of adaptation, respectively, whereas populations $\mathrm{M}$ and $\mathrm{R}$ were at the 4th generation after the final election cycle. Thus, population $\mathrm{R}$ displayed the desired phenotype characteristics by damaging all four differential varieties. Meanwhile, population T, M, and A exhibited deviation from the expected biotype 1, 2, and 3 virulence character, respectively, i.e., population $\mathrm{T}$ and $\mathrm{M}$ showed biotype 4 virulence character, and population $A$ have the same virulence characteristics to that of population $R$.

\section{Polymerase chain reaction}

Genomic DNAs from 10 females per population available from a previous study (Chaerani et al. 2021) were used in the current study. A total of 89 primer combinations of the forward primer $\mathrm{Me}$ (Me01 to Me25) and the reverse Em primers (Em01 to Em16, Em18 to Em27, and Em30 to Em36) were selected from the list of 106 polymorphic SRAP primers in the cross of $\mathrm{BPH}$ biotype 1 and biotype 2 (Jing et al. 2014). Polymorphism tests of the primers were performed on a DNA pool made from equal concentration $(10 \mathrm{ng} / \mu \mathrm{l})$ of randomly selected five female samples per population. PCR amplification was performed on a thermal cycler (Bio-Rad) in $10-\mu 1$ reaction 
volumes containing 1x PCR buffer, $1 \mathrm{mM}$ of dNTP, $0.3 \mathrm{M}$ of each forward and reversed primer, $0.5 \mathrm{U}$ of Taq DNA polymerase (DreamTaq), and $10 \mathrm{ng} / \mu \mathrm{l}$ of pooled DNA. The PCR cycling profile is as described in Jing et al. (2014), wherein the first few cycles, low-temperature annealing ( 35C) was employed, and a higher annealing temperature $(\sim 50 \mathrm{C})$ was used in the following processes. PCR products were fractionated by electrophoresis on $4 \%$ agarose gels in $0.5 \% \mathrm{TBE}$ for $4 \mathrm{~h}$ at a constant current of $100 \mathrm{~V}$. DNA bands were visualized under a UV trans-illuminator (GelDoc Bio-Rad) after being stained with $0.5 \mu \mathrm{g} / \mathrm{l} \mathrm{EtBr}$ solution. Primers yielded polymorphic bands were further used for individual PCR amplification of a total 40 females. PCR product separation was performed by electrophoresis on $8 \%$ non-denaturing polyacrylamide gels in $1 \%$ TBE for 80 minutes at a constant current of $90 \mathrm{~V}$. Gels were stained in $\mathrm{EtBr}$ solution before visualization under a UV transilluminator.

\section{Data analysis}

DNA bands with the same mobility were scored dominantly by eye as " 1 " for the presence or " 0 " for absence. Differences in band intensity were ignored. The distinguishing ability of SRAP markers in assessing genetic diversity was evaluated based on polymorphic information content (PIC) values calculated using PowerMarker V 3.25 (Liu and Muse 2005). Genetic diversity parameters, including the number of observed alleles $(\mathrm{Na})$, number of effective alleles (Ne), Shannon's information index (I), and population heterozygosity as measured by observed heterozygosity (Ho), expected heterozygosity (He), and unbiased heterozygosity (UHe) was estimated using GenAlex 6.5 (Peakall and Smouse 2012). This software was also employed to assess genetic differentiation among and within populations by analyzing of molecular variance (AMOVA) based on 999 random permutation and pairwise PhiPT population values. In contrast, genetic relatedness among populations was assessed by multivariate principal coordinate analysis (PCoA).

\section{RESULTS AND DISCUSSION}

\section{Marker diversity}

Eighty nine SRAP primer combinations were employed for polymorphism tests. Among these primers, 24 (27\%) yielded polymorphic bands, $10 \quad(11 \%)$ produced monomorphic bands, 25 (28\%) primers yielded inconsistent and unclear bands, and the remaining primers failed to amplify DNA. Of the polymorphic primers, 18 (20\%) primers derived from the combination of 11 forward and 9 reverse primers produced precise amplification (Table 1), and hence they were used in genotyping of 40 BPH samples.

The observed low primer polymorphism rate could be partly explained by the use of $4 \%$ agarose gels for primer screening, rather than polyacrylamide gels which can provide a more satisfactory resolution of DNA bands and hence more number of scoreable bands. SRAP fingerprint results are primarily determined by $\mathrm{PCR}$ amplification conditions, electrophoresis systems, and primer combination choice (Li et al. 2014). SRAP fractionation on acrylamide gels is preferred to analyze amplicons of $\sim 100$ 1000 bp (Li et al. 2014).

The polymorphic SRAP primer combinations amplified multiple polymorphic fragments, with the total number of polymorphic DNA fragments was 265 and ranged from 10 (primer Me21Em09) to 21 (primer Me19Em13) and an average of 15 bands per primer (Table 1). An example of SRAP amplification is depicted in Figure 1. On average, 15 polymorphic fragments per primer were amplified. In addition, a wide range of band sizes was observed, from 95 to $625 \mathrm{bp}$ (Table 1). SRAP primers quickly generate polymorphic fragments because of variations in primer binding sites in exon and intron regions among different individuals (Jing et al. 2014). However, despite causing a large number of polymorphic fragments, these polymorphic SRAP markers were, on average, not informative (PIC $<0.25$ ), and only two markers (Me19EM20 and Me21Em09) were slightly informative $(0.25<\mathrm{PIC}<0.50)$ (Botstein et al. 1980). The resulting low PIC values could be explained by the selection of primers or the narrow genetic differences among the material studied (Alzahib et al. 2021).

\section{Population genetic parameter}

The mean percentage of polymorphic markers among populations was moderate $(61 \%)$, with the lowest $(49 \%)$ and highest $(73 \%)$ percentages were observed in populations $\mathrm{R}$ and $\mathrm{A}$, respectively (Table 2). The values of genetic diversity parameters were almost equal among the populations (the range of $\mathrm{Na}$ values were 1.1 to $1.4, \mathrm{Ne} 1.2$ to 1.3 , I 0.22 to 0.29 , He 0.14 to 0.18 , and UHe 0.15 to $0.19)$.

Table 1. Features of polymorphic SRAP markers used in genetic analysis of four brown planthoppers (Nilaparvata lugens Stål) populations adapted on differential host rice varieties

\begin{tabular}{lccc}
\hline $\begin{array}{c}\text { Primer } \\
\text { combination }\end{array}$ & $\begin{array}{c}\text { N polymorphic } \\
\text { band }\end{array}$ & PIC & $\begin{array}{c}\text { Range of } \\
\text { allele size (bp) }\end{array}$ \\
\hline Me19Em20 & 13 & 0.31 & $110-412$ \\
Me21Em09 & 10 & 0.26 & $102-597$ \\
Me16Em13 & 11 & 0.24 & $129-454$ \\
Me22Em05 & 14 & 0.23 & $111-527$ \\
Me10Em07 & 15 & 0.23 & $141-542$ \\
Me22Em12 & 20 & 0.21 & $105-465$ \\
Me25EM11 & 15 & 0.20 & $121-481$ \\
Me04Em10 & 15 & 0.19 & $120-553$ \\
Me08Em05 & 18 & 0.19 & $106-591$ \\
Me03Em07 & 16 & 0.18 & $96-515$ \\
Me11Em13 & 11 & 0.18 & $109-387$ \\
Me19Em13 & 21 & 0.18 & $138-486$ \\
Me11Em05 & 15 & 0.18 & $95-510$ \\
Me10Em12 & 12 & 0.17 & $129-596$ \\
Me19Em12 & 14 & 0.17 & $117-429$ \\
Me22Em04 & 18 & 0.16 & $130-625$ \\
Me14Em05 & 16 & 0.15 & $105-568$ \\
Me04Em13 & 14 & 0.14 & $115-521$ \\
Mean & 15 & 0.20 & \\
\hline
\end{tabular}

Note: PIC is polymorphic information content, an average of 40 female insects 
Nevertheless, there is a tendency that populations $\mathrm{R}$ and A showed the lowest and highest value of genetic diversity parameters, respectively, according to the percentage of polymorphic markers. In general, the importance of genetic diversity parameters did not represent the respective virulence characteristics of each population. For instance, populations $\mathrm{A}$ and $\mathrm{R}$ with higher virulence characteristics than populations $\mathrm{T}$ and $\mathrm{M}$ showed contrasting genetic diversity values.

All populations had private alleles, i.e., allele unique to a single population. Being low in frequency and occurring in one or more populations, private alleles can be used to identify populations by combining some genetic loci (Alzahib et al. 2021). The number of private alleles in our studied population was high and equal between population $\mathrm{T}$ and $\mathrm{R}$ ( 8 and 9 , respectively) and between population $\mathrm{M}$ and A (17 and 16, respectively). Therefore, private alleles in our populations do not represent a population identity but may be the result of slippage and proofreading errors during DNA replication that primarily changes the arrangement of DNA nucleotides (Alzahib et al. 2021).

\section{Population structure}

AMOVA indicated that only $9 \%$ of the total variation was attributed to differences among populations (Table 3). This rate among-population genetic variation is similar
(11\%) to that obtained from AMOVA of the same four populations using SSR markers (Chaerani et al. 2021). Both values are much lower than the genetic variation among biotypes 1, 2, 3, and Y, which accounted for $25.5 \%$ of the total variation (Jing et al. 2014). Thus, the low genetic divergence among populations could result from early host adaptation of individuals selected from a common source of field populations. Nevertheless, the overall PhiPT value was greater than zero $(0.088)$ and significant $(P<0.001)$ (Table 3$)$, indicating the presence of some genetic divergences among populations $(\mathrm{Xu}$ et al. 2016).

Further analysis based on pairwise PhiPT population values, which provide estimates of genetic distances between pairs of populations, obtained a range of PhiPT values from 0.057 to 0.133 . The highest genetic differentiation (PhiPT 0.133) was observed between population $\mathrm{T}$ and $\mathrm{R}$, and the lowest (PhiPT 0.057) was between population $\mathrm{T}$ and $\mathrm{M}$ (Table 4). These values indicate moderate differentiation among the population based on the threshold of $0.05<\mathrm{PhiPT} \leq 0.15$ (Wang et al. 2020). However, between all pairs of populations, there was significant genetic differentiation $(P=0.01)$ (Table 4$)$. Therefore, genetic adaptation on the host may have partially occurred and been observed as two virulence characters among the four populations.

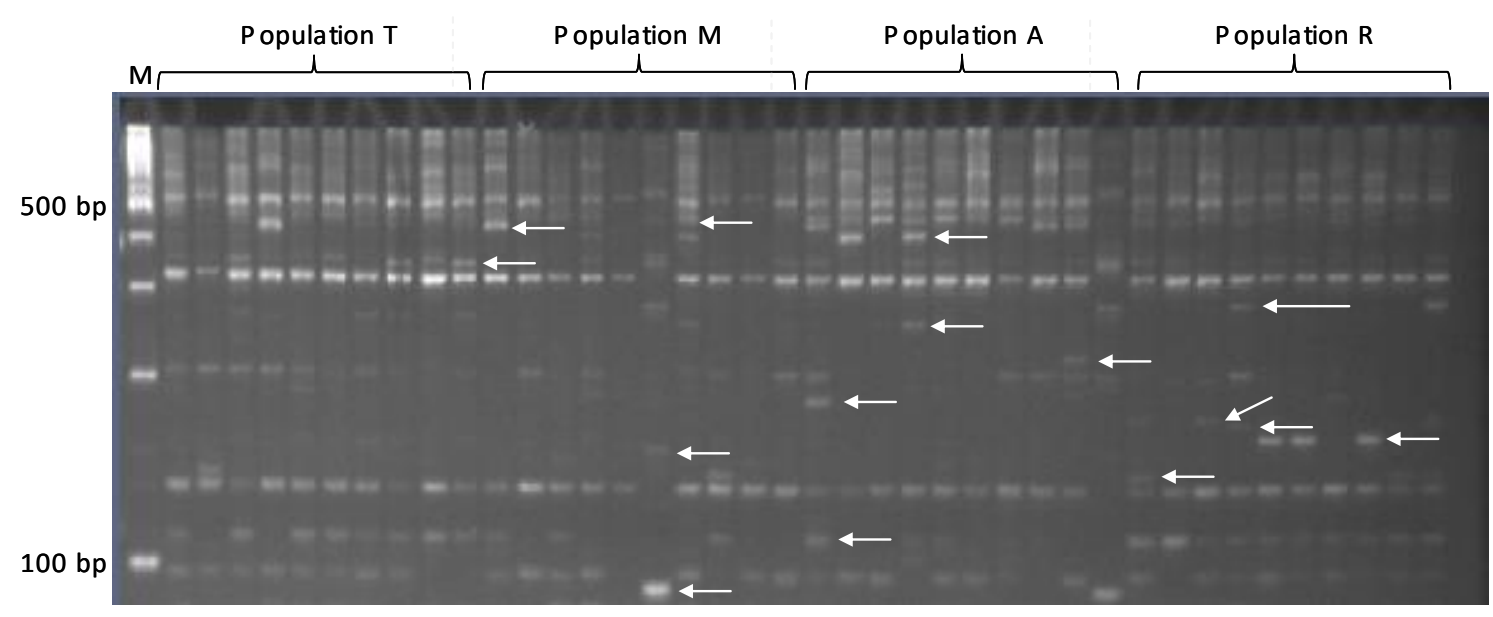

Figure 1. An example of PCR products of four rice brown planthopper (Nilaparvata lugens Stål) populations $(n=10)$ generated by SRAP primer combination of $\mathrm{Me} 03$ and Em07 separated on $8 \%$ non-denaturing polyacrylamide gel. Population T, M, A, and R were adapted on TN1 (carries no Bph gene), Mudgo (Bphl), ASD7 (bph2), and Rathu Heenathi (Bph3, Bph17), respectively. Arrows indicate polymorphic DNA bands. $\mathrm{M}=100 \mathrm{bp}$ size marker.

Table 2. Population genetic parameters for brown planthopper (Nilaparvata lugens Stål) populations adapted on differential host rice varieties based on 268 loci derived from 18 polymorphic SRAP markers

\begin{tabular}{lccccccc}
\hline Population (host variety and resistance gene) & $\mathbf{P}(\boldsymbol{\%})$ & Na & Ne & I & He & UHe & Pa \\
\hline T (TN1 [carries no Bph gene]) & 53.9 & 1.1 & 1.2 & 0.23 & 0.15 & 0.16 & 8 \\
M (Mudgo [Bphl]) & 68.0 & 1.4 & 1.3 & 0.26 & 0.16 & 0.17 & 17 \\
A (ASD7 [bph2]) & 73.1 & 1.5 & 1.3 & 0.29 & 0.18 & 0.19 & 16 \\
R (Rathu Heenathi [Bph3, Bph17]) & 49.2 & 1.1 & 1.2 & 0.22 & 0.14 & 0.15 & 9 \\
Mean & $61.0 \pm 5.7$ & $1.3 \pm 0.03$ & $1.3 \pm 0.01$ & $0.25 \pm 0.01$ & $0.16 \pm 0.01$ & $0.17 \pm 0.01$ & $12.5 \pm 4.65$ \\
\hline
\end{tabular}

Note: Values for each population are mean from 10 females. P: polymorphic locus, Na: number of different alleles, Ne: number of effective alleles, I: Shannon's information index. 


\section{Genetic relationship}

Results from PCoA are three bi-plots with the first, second, and third axis accounted for $24.7 \%, 20.6 \%$, and $18.1 \%$ of the total variation explained, respectively (Figure 1). Two partial clusters were observed: one group consisted of most individuals from populations $\mathrm{T}$ and $\mathrm{M}$, whereas the other cluster contained most members of populations $\mathrm{A}$ and R. Most individuals from the same population tended to aggregate. This partial clustering corresponds to two virulence patterns observed among the populations, i.e., biotype 4 (population $\mathrm{T}$ and $\mathrm{M}$ ) and the highly virulent phenotype (population A and R).

Virulence phenotype results from complicated interactions between herbivores and plant hosts or between defense and virulence mechanisms (Horgan 2018). BPH virulence adaptation is mediated by the endosymbiont yeast-like symbiont and bacteria, which compensate for the antifeedant effect in the host and provide the nutrition necessary for BPH reproduction and egg development (Chen et al. 2011; Ferrater et al. 2013; Fan et al. 2015). During the early virulence adaptation on resistant variety, abundant and high diversities of microbial endosymbionts are present in $\mathrm{BPH}$ females feeding on a resistant rice variety compared to that feeding on a susceptible variety, but once BPH has overcome the host resistance, endosymbiont density is reduced (Chen et al. 2011; Ferrater et al. 2015). Therefore, endosymbionts have an essential role in the adaptation and survival but do not determine BPH virulence. The complementary interaction between $\mathrm{BPH}$ and its endosymbionts has been proved by genome sequencing of $\mathrm{BPH}$, which reveals that missing genes essential in biochemical pathways for its survival on the nutritionally imbalanced sap diet are present in the genomes of its microbial endosymbionts (Bao and Yang 2019).

Table 3. Results of analysis of molecular variance (AMOVA) for 40 females of four brown planthoppers (Nilaparvata lugens Stål) adapted on differential host rice varieties based on 268 loci derived from 18 SRAP markers

\begin{tabular}{llllll}
\hline Source & df & SS & MS & Estimates of variance components & Molecular variance $(\%)$ \\
\hline Among Pops & 3 & 171.700 & 57.233 & 2.812 & 9 \\
Within Pops & 36 & 1047.900 & 29.108 & 29.108 & 91 \\
& & & & 31.921 & 100 \\
Total & 39 & 1219.600 & & & \\
Stat & Value & $P($ rand $>=$ data $)$ & & & \\
PhiPT & 0.088 & 0.001 & & &
\end{tabular}

Table 4. Pairwise population PhiPT values among four brown planthopper (Nilaparvata lugens Stål) populations adapted on differential host rice varieties.

\begin{tabular}{lcccc}
\hline Population (host variety and resistance gene) & T & M & A & R \\
\hline T (TN1 [carries no Bph gene]) & $\ldots$ & 0.01 & 0.01 & 0.01 \\
M (Mudgo [Bphl]) & 0.057 & $\ldots$ & 0.01 & 0.01 \\
A (ASD7 [bph2]) & 0.090 & 0.063 & $\ldots$ & $\ldots .069$ \\
R (Rathu Heenathi [Bph3, Bph17]) & 0.133 & 0.117 & $\ldots$ \\
\hline
\end{tabular}

Note: PhiPT values are below diagonal, whereas probability values based on 999 permutations are shown above diagonal
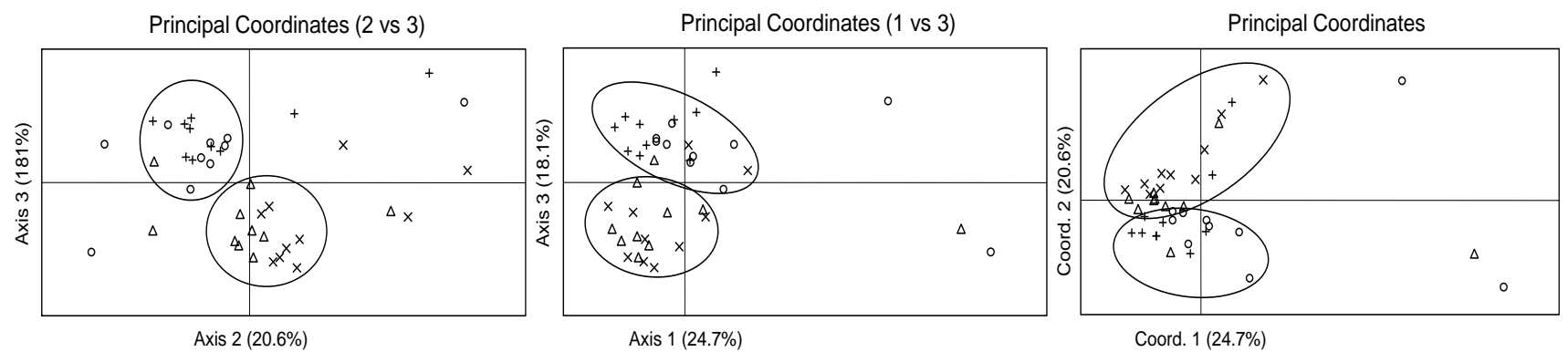

Figure 2. Bi-plots of principal coordinate analysis (PCoA) of brown planthopper population $\mathrm{T}$ ('‘'), M (' $\circ$ '), A (' $\left.\Delta^{\prime}\right)$, and $\mathrm{R}$ (' $\times$ ') adapted on differential rice host varieties TN1 (no Bph gene), Mudgo (Bph1), ASD7 (bph2), and Rathu Heenathi (Bph3, Bph17), respectively. 
Two independent genetic mapping studies on inbred populations of biotype 1 and 2 identified a significant, recessive virulence gene associated and three QTLs explaining considerable phenotypic variation on virulence and BPH growth rate, respectively (Jing et al. 2014; Kobayashi et al. 2014). In addition, molecular analysis of two BPH biotypes revealed differential expression profiles of genes related to digestion, saliva secretion, detoxification, metabolisms of lipid, carbohydrate, amino acid, and nitrogen; signaling pathways of defense, stress, and immunity responses (Yu et al. 2014), as well as variations in nucleotide and amino acid substitutions in mitochondrial protein-coding genes (Lv et al. 2015).

Regarding population genetics, differences between BPH biotype populations reflect differences in allele frequencies of virulence genes associated with host adaptation (Kobayashi 2016). A BPH biotype consists of individuals who differ in virulence. Increased or decreased proportion determines the population's virulence phenotypes associated with the host adaptation through selection and sympatric speciation (Kobayashi 2016). Thus, virulence selection and adaptation can change the virulence character of a BPH population. However, virulence adaptation can be partial or complete (Horgan 2018). In leafhopper, partial transformation can occur as little as 5-6 generations of selection ( $\mathrm{Vu}$ et al. 2014). Our BPH populations, which were in the 2 nd to 4 th generation after the final virulence selection cycle or the 5th to 7 th generation after the first election cycle, were at the state of partial virulence adaptation on its host as revealed by the presence of two, instead of four, virulence phenotypes. Interestingly, SRAP analysis partially clustered the four $\mathrm{BPH}$ populations into two PCoA plots that corresponded with the two virulence groups. Therefore, apart from its analogy to the morphological character (Robarts and Wolfe 2014), SRAP markers also can elucidate markers with inherent biological significance, including phenotypes (Liao et al. 2016).

Preexisting virulence or avirulence genes at low frequencies could be removed from the population selection (Kobayashi 2016). Kobayashi (2016) reviewed that genotypes can lose their virulence to $B p h 1$ or $b p h 2$ genes by removing virulent individuals to $B p h 1$ for two generations or to $b p h 2$ for three generations of selection, respectively. For our case, a longer adaptation period would be needed to remove virulent individuals from populations $\mathrm{T}, \mathrm{M}$, and $\mathrm{A}$, intended to have biotype 1, 2, and 3 virulence characteristics. Our populations were developed from field populations that potentially have high proportion virulence alleles (Kobayashi 2016). The selection process is critical because mixtures or contamination in the population can generate conflicting results in subsequent investigation using different virulence test methods, i.e., standard seedbox screening tests, honeydew excretion, and body weight measurement (Kobayashi 2016). On the contrary, more virulent phenotypes can be developed by continuous host adaptation without an artificial virulence selection process, similar to that observed in the field. Laboratory and field experiments showed that 5 to 33 generations of constant transformation on a single variety could generate a virulent population that was previously unable to damageresistant types (Nemoto and Yokoo 2002; Cruz et al. 2011; Jing et al. 2012).

The current study revealed low genetic variation with minor but significant genetic differentiation among the four $\mathrm{BPH}$ populations. The 18 polymorphic SRAP markers employed have been proved for their utility in separating the populations into two clusters concordant with the two virulence phenotypes present among populations. Concerning virulence phenotype, population $\mathrm{R}$ can represent a field population used in the resistance screening of rice lines. However, these four populations are not ready to be used as resistance screening agents because of incomplete genetic separation. Continued virulence selection and adaptation on the host is necessary to result in the desired four virulence phenotypes with complete genetic differentiation.

\section{ACKNOWLEDGEMENTS}

Financial support was provided through DIPA ICABIOGRAD 2016. In addition, we are grateful to $\mathrm{M}$. Saputro and Riko Harmando for insect rearing in the glasshouse.

\section{REFERENCES}

Alzahib RH, Migdadi HM, Al Ghamdi AA, Alwahibi MS, Afzal M, Elhanty EH, Aghamdi SS. 2021. Exploring genetic variability among and within hail tomato landraces based on sequence-related amplified polymorphism markers. Diversity 13(3): 135. DOI: 10.3390/d13030135.

Baehaki S. 2012a. Development of brown planthopper biotype on rice plant. Iptek Tan Pangan 7(1): 8-17. [Indonesian]

Baehaki S. 2012b. Standard Operational Procedure of Rice Line and Variety Trial to Brown Planthopper (Nilaparvata lugens). Indonesian Center for Rice Research, Subang. [Indonesian]

Baehaki S, Munawar D. 2008. Identification of brown planthopper biotype in Java, Sumatera and Sulawesi and resistance reaction of rice cultivars. In: Suprihatno (eds). Proceeding Seminar Appreciation of Rice Research Supports P2BN. Indonesian Research Center for Rice, Subang, 19-20 November 2007. [Indonesian]

Baehaki SE, Mejaya JM. 2015. Brown planthopper as highly economical global pest and its control strategy. Iptek Tan Pangan 9(1): 1-12. [Indonesian]

Bahagiawati AH, Rijzaani H. 2005. Clustering of brown planthopper biotype based on RAPD-PCR. Hayati 12(1): 1-6. DOI: 10.1016/S1978-3019(16)30315-1. [Indonesian]

Bao Y-y, Zhang C-xi. 2019. Recent advances in molecular biology research of a rice pest, the brown planthopper. J Integrative Agric 18(4): 716-728. DOI: 10.1016/S2095-3119(17)61888-4.

Botstein D, White RL, Skolnick M, Davis RW. 1980. Construction of a genetic linkage map in man using restriction fragment length polymorphisms. Am J Hum Gen 32: 314-331.

Bottrell DG, Schoenly KG. 2012. Resurrecting the ghost of green revolutions past: The brown planthopper as a recurring threat to highyielding rice production in tropical Asia. J Asia-Pacific Entomol 15(1): 122-140. DOI: 10.1016/j.aspen.2011.09.004.

Chaerani, Damayanti D, Trisnaningsih, Yuriyah S, Kusumanegara K, Dadang A, Sutrisno, Bahagiawati. 2016. Virulence of brown planthopper and development of core collection of the pest. J Pen Pert Tan Pangan 35(2): 109-118. [Indonesian]

Chaerani, Dadang A, Sutrisno, Bahagiawati AH, Yunus M. 2021. Virulence and SSR diversity of brown planthopper (Nilaparvata 
lugens) adapted on differential rice host varieties. Hayati J Biosci 28(4): 293-303. [in press]

Chaerani, Fatimah, Damayanti D, Dadang A, Sutrisno, Bahagiawati. 2017. Selection of brown planthopper biotype (Nilaparvata lugens Stål). In: Rumanti I, Susanto U, Usyati N, Nuryanto B, Ruskandar A, Widyantoro (eds). Breakthrough Innovation in Rice Technology Adapted to Climate Change Supports Food Sovereignity. Indonesian Research Center for Rice, Sukamandi, 31 August, 2016. [Indonesian]

Chen YH, Bernal CC, Tan J, Horgan F, Fitzagerald MA. 2011 Planthopper "adaptation" to resistant rice varieties: Changes in amino acid composition over time. J Insect Physiol 57(10): 1375-1384. DOI: 10.1016/j.jinsphys.2011.07.002.

Cheng X, Zhu L, He G. 2013. Towards understanding of molecular interactions between rice and the brown planthopper. Mol Plant 6(3): 621-634. DOI: $10.1093 / \mathrm{mp} / \mathrm{sst} 030$.

Cruz AP, Arida A, Heong KL, Horgan FG. 2011. Aspects of brown planthopper adaptation to resistant rice varieties with the Bph3 gene. Entomol Exp Appl 141(3): 245-257. DOI: 10.1111/j.15707458.2011.01193.x.

ElAzim AMA, Khashaba EH, Ibrahim SA. 2019. Genetic polymorphism among seven entomopathogenic nematode species (Steinernematidae) revealed by RAPD and SRAP analyses. Egyptian J Biol Pest Control 29(1): 1-7. DOI: 10.1186/s41938-019-0114-z.

Fan HW, Noda H, Xie H-Q, Suetsugu Y, Zhu Q-H, Zhang C-X. 2015. Genomic analysis of an ascomycete fungus from the rice planthopper reveals how it adapts to an endosymbiotic lifestyle. Genome Biol Evol 7(9): 2623-2634. DOI: 10.1093/gbe/evv169.

Ferrater JB, de Jong PW, dicke M, Chen YH, Horgan FG. 2013. Symbiont-mediated adaptation by planthoppers and leafhoppers to resistant rice varieties. Arthropod-Plant Interact 7(6): 591-605. DOI: 10.1007/s11829-013-9277-9.

Ferrater JB, Naredo AI, Almazan MLP, de Jong PW, Dicke M, Horgan FG. 2015. Varied responses by yeast-like symbionts during virulence adaptation in a monophagous phloem-feeding insect. Arthropod-Plant Interact 9(3): 215-224. DOI: 10.1007/s11829-015-9373-0.

Horgan FG, Srinivasan TS, Bentur JS, Kumar R, Bhanu KV, Sarao PS, Chien HV, Almazan MLP, Bernal CC, Ramal AF, Ferrater JB, Huang S-H. 2017. Geographic and research center origins of rice resistance to asian planthoppers and leafhoppers: Implications for rice breeding and gene deployment. Agronomy 7(4): 62. DOI 10.3390/agronomy7040062.

Horgan FG. 2018. Integrating gene deployment and crop management for improved rice resistance to Asian planthoppers. Crop Prot 110: 21-33. DOI: 10.1016/j.cropro.2018.03.013.

Horgan FG, Ramal AF, Bentur JS, Kumar R, Bhanu KV, Sarao PS Iswanto EH, Chien HV, Phyu MH, Bernal CC, Almazan MLP, Alam MZ, Lu Z, Huang S-H. 2015. Virulence of brown planthopper (Nilaparvata lugens) populations from South and South East Asia against resistant rice varieties. Crop Prot 78: 222-231. DOI: 10.1016/j.cropro.2015.09.014.

Jing S, Liu B, Peng L, Peng X, Zhu L, Fu Q, He G. 2012. Development and use of EST-SSR markers for assessing genetic diversity in the brown planthopper (Nilaparvata lugens Stål). Bull Entomol Res 102(1): 113-122. DOI: 10.1017/S0007485311000435.

Jing S, Zhang L, Ma Y, Liu B, Zhao Y, Yu H, Zhou X, Qin R, Zhu L, He G. 2014. Genome-wide mapping of virulence in brown planthopper identifies loci that break down host plant resistance. PLoS ONE 9(6): e98911. DOI: 10.1371/journal.pone.0098911.

Kobayashi T. 2016. Evolving ideas about genetics underlying insect virulence to plant resistance in rice-brown planthopper interactions. J Insect Physiol 84: 32-39. DOI: 10.1016/j.jinsphys.2015.12.001.

Kobayashi T, Yamamoto K, Suetsugu Y, Kuwazaki S, Hattori M, Jairin J, Sanada-Morimura S, Matsumura M. 2014. Genetic mapping of the rice resistance-breaking gene of the brown planthopper Nilaparvata lugens. Proc Royal Soc B: Biol Sci 281: 1787.

Li G, Quiros CF. 2001. Sequence-related amplified polymorphism (SRAP), a new marker system based on a simple PCR reaction: Its application to mapping and gene tagging in Brassica. Theor Appl Genet 103 (2-3): 455-461.

Li XY, Li J, Zhao ZJ, Yang F, Fu QW, Liu HS, Wang DD, Yang YC, Wang RY. 2014. Sequence-related amplified polymorphism (SRAP) for studying genetic diversity and population structure of plants and other living organisms: A protocol. J Anim Plant Sci 24(5): 14781486 .

Liao B, Wang F, Chen L, Li P, Ouyang K, Pian R, Liu M, Que Q, Zhou X, Xi W, Chen X. 2016. Population structure and genetic relationships of Melia Taxa in China assayed with sequence-related amplified polymorphism (SRAP) markers. Forests 7(4): 1-15. DOI: 10.3390/f7040081.

Liu K, Muse SV. 2005. PowerMaker: An integrated analysis environment for genetic maker analysis. Bioinformatics 21(9): 2128-2129. DOI: 10.1093/bioinformatics/bti282.

Longya A. Talumphai S, Jantasuriyarat C. 2020. Morphological characterization and genetic diversity of rice blast fungus, Pyricularia oryzae, from thailand using ISSR and SRAP markers. J Fungi 6(1): 38. DOI: 10.3390/jof6010038.

Lv L, Peng X, Jing S, Liu B, He G. 2015. Intraspecific and interspecific variations in the mitochondrial genomes of Nilaparvata (Hemiptera: Delphacidae). J Econ Entomol 108(4): 2021-2029. DOI:10.1093/jee/tov122.

Manzila I, Rijzaani H, Bahagiawati. 2000. Purification of laboratory brown planthopper biotypes. In: Mariska I, Somantri IH, Samudra IM, Ambarwati AD, Prasetiyono J, Orbani IN (eds). Prosiding Seminar on Results of Pioneering Research and Plant Biotechnology. Bogor, 26-27 Desember 2001. [Indonesian].

Nemoto H, Yokoo M. 2002. Experimental selection of a brown population on mixtures of resistant rice lines. Breed Sci 44: 133-136. DOI: 10.1270/jsbbs1951.44.133.

Peakall P, Smouse R. 2012. GenAlEx 6.5: Genetic analysis in Excel. Population genetic software for teaching and research-an update. Bioinformatics 28(19): 2537. DOI: 10.1093/bioinformatics/bts460.

Robarts DWH, Wolfe AD. 2014. Sequence-related amplified polymorphism (SRAP) markers: A potential resource for studies in plant molecular biology. App Plant Sci 2(7): 1400017. DOI: 10.3732/apps. 1400017.

Sasmita P, Satoto, Rahmini, Agustiani N, Handoko DD, Suprihanto, Guswara A, Suharna. 2019. Description of Superior Rice Varieties. Indonesian Center for Food Crops Research and Development, Sukamandi. [Indonesian]

Shufran K, Whalon M. 1995. Genetic analysis of brown planthopper biotypes using random amplified polymorphid DNA-polymerase chain-reaction (RAPD-PCR). Int J Trop Insect Sci 16(1): 27-33. DOI: $10.1017 / \mathrm{S} 1742758400018282$.

Tripathi A, Dubey SC. 2015. Sequence-related amplified polymorphismPCR analysis for genetic diversity in Rhizoctonia solani populations infecting pulse crops in different agro-ecological regions of India. Plant Pathol J 14(4): 234-242. DOI: 10.3923/ppj.2015.234.241.

Vu Q, Quintana R, Fujita D, Bernal CC, Yasui H, Medina CD, Horgan FG. 2014. Responses and adaptation by Nephotettix virescens to monogenic and pyramided rice lines with Grh-resistance genes. Entomol Exp Appl 15(2): 179-190. DOI: 10.1111/eea.12149.

Wang D, Shi X, Liu D, Yang Y, Shang Z. 2020. Genetic divergence of two sitobion avenae biotypes on barley and wheat in China. Insects 11(2): 1-17. DOI: 10.3390/insects11020117.

Xu Y, Cai N, Woeste K, Kang X, He C, Li G, Chen S, Duan A. 2016. Genetic diversity and population structure of Pinus yunnanensis by Simple Sequence Repeat Markers. Forest Sci 62(1): 38-47. DOI: 10.5849/forsci.15-064.

Yu H, Ji R, Ye W, Chen H, Lai W, Fu Q, Lou Y. 2014. Transcriptome analysis of fat bodies from two brown planthoppers (Nilaparvata lugens) populations with different virulence levels in rice. PLoS ONE 9 (2): e88528. DOI: 10.1371/journal.pone.0088528. 